

Some People Feel the Rain, Others Just Get Wet: An Analysis of Regional Differences in the Effects of Weather on Cycling

by

Kathrin Goldmann and Jan Wessel

Institute of Transport Economics Münster

Working Paper

No. 33

July 2020 
(c) Westfälische Wilhelms-Universität (WWU),

Institute of Transport Economics, 2020

\section{Address}

Institut für Verkehrswissenschaft

Am Stadtgraben 9

D 48143 Münster, Germany

\section{Telephone}

+4925183-22994

Fax

+4925183-28395

\section{E-Mail}

verkehrswissenschaft@uni-muenster.de

\section{Website}

http://www.iv-muenster.de

\section{All rights reserved.}

Any reproduction, publication and reprint in the form of a different publication, whether printed or produced electronically, in whole or in part, is permitted only with the explicit written authorisation of the Westfälische WilhelmsUniversität, Institute of Transport Economics, or the author(s).

The views expressed in this paper do not necessarily reflect those of the Institute of Transport Economics or the WWU.

The Working Paper Series seeks to disseminate economic research work by the WWU, Institute of Transport Economics staff and visitors. Papers by researchers not affiliated with the WWU Institute of Transport Economics may also be considered for publication to the extent that they have been presented at research seminars/workshops organised by the institute.

The working papers published in the Series constitute work in progress circulated to stimulate discussion and critical comments. Views expressed represent exclusively the authors' own opinions.

The Series is managed by the Director of the Institute of Transport Economics. 


\title{
Some People Feel the Rain, Others Just Get Wet: An Analysis of Regional Differences in the Effects of Weather on Cycling
}

\author{
By Kathrin Goldmann* and Jan Wessel*
}

\begin{abstract}
Between cities and regions, not only cycling levels differ, but also the reactions of cyclists to adverse weather conditions. Using data from 122 automated bicycle counting stations in 30 German cities, and a composite index of adverse weather conditions that consists of air temperature, precipitation, wind speed, relative humidity, and cloud coverage, we calculate city-specific weather elasticities of the level of utilitarian cycling. The results show that these weather elasticities vary significantly between cities. Our next step is to analyze various determinants of weather elasticities, which reveals that the share of young inhabitants and the density of the cycle network have a positive impact on weather resilience. Based on the notion that resilience to adverse weather conditions reflects a revealed part of a city's bicycle culture, the weather elasticities can be used to create a ranking of bicycle cities. This ranking is positively correlated with a ranking based on the modal share of cycling, as well as with other rankings based on stated preference surveys or external conditions such as infrastructure or cycling safety.
\end{abstract}

$J E L: R 49$.

Keywords: Bicycle, weather elasticities, Germany, regional heterogeneity, bicycle city ranking, cycling culture.

\section{Introduction}

Cycling is gaining more and more attention from public authorities as a means of urban transport. For decades, cycling in most cities in Germany was regarded essentially as a leisure time activity on sunny Sundays. However, the increase in traffic congestion in connection with the related problem of air pollution in the cities has shifted the manner in which this mode of transport is viewed.

Traffic congestion is increasingly problematic for cities all over the world, and certainly also for Germany. In the larger German cities like Hamburg, Berlin, Munich, Nuremberg, and Stuttgart, the congestion level is at $30 \%$ or above, implying that a trip takes on average at least $30 \%$ longer than it would under freeflow conditions (TomTom, 2019). Another analysis has found that the average travel speed in the cities has decreased by $1.2 \%$ per year between 2015 and 2018 (ADAC, 2019).

The environmental organization Deutsche Umwelthilfe (DUH) has sued several cities in Germany for exceeding the limit of $40 \mathrm{\mu g}$ NOx (nitrogen oxide) at the metering stations. In order to avoid a ban of diesel cars, several cities were forced

\footnotetext{
* Westfälische Wilhelms-Universität Münster, Institute of Transport Economics, Am Stadtgraben 9, 48143 Münster, Germany.

The final publication in "Research in Transportation Business \& Management" is available online at: https://doi.org/10.1016/j.rtbm.2020.100541
} 
to take rapid action. However, the prohibition of car traffic on lanes close to the metering stations and opening them to public transport and non-motorized traffic turned out to be an easy but evasive solution, which failed to tackle the real problem. Moreover, traffic control systems have been used to limit the inflow of cars. Traffic jams outside the cities, however, have become even worse, as those measures have reduced the road capacity for cars. Adequate alternative means of transport could often not be established within a short timeframe.

As a consequence, the debate about traffic congestion and air pollution in German cities has shifted its focus to transport modes with zero local emissions. A very promising mode of transport, especially for short distances, is cycling, as it also uses significantly less space than car transport. To date, however, the modal share of cycling varies significantly between German cities.

We can see that there are a few cities where the modal share of cycling is already quite high, while it remains lower for others. Germany's national cycling association, the Allgemeiner Deutscher Fahrrad-Club (ADFC), conducts an annual survey to evaluate the cycling conditions in various German cities. Participants of the "ADFC-Fahrradklima-Test" (ADFC bicycle climate test) can rate their satisfaction with regard to daily aspects of cycling, such as dedicated infrastructure, safety, or risk of theft. From this information, a final grade is calculated for each city. Based on these grades, the cities are ranked and the one with the best grade often claims the nickname "bicycle capital" for itself.

Following this train of thought, the bicycle capital is the city that offers the best conditions for riding regularly and safely by bike. In this paper, however, we propose a different approach to assigning the title of bicycle capital, which is not based on the quality of infrastructure or political conditions within a city, but rather attempts to capture how well established the usage of bicycles is within a particular city. Specifically, the aim of this paper is threefold:

First, we propose a different approach to measuring whether a city is a $b i$ cycle city or not. Our approach differs from others in that it does not require stated preference survey data or detailed infrastructural information. Using regular traffic counter data and weather data, we can estimate city-specific weather elasticities, which reflect the changes in bicycle traffic that are caused by adverse weather conditions. Thereby, we can observe if some form of bicycle culture has emerged within a city, so that the bicycle is even used frequently under bad weather conditions, or if the bicycle is regarded more as a transport mode for good weather only. Following this approach, the city in which bicyclists are least sensitive to adverse weather conditions could be crowned as the bicycle capital, because the people there use their bicycles regardless of the weather conditions. Thus, cycling as a means of transport is already ingrained in their daily trips and routines.

Second, we analyze factors that could influence these weather elasticities. We can thereby obtain information on the factors that are associated with a high resilience to bad weather conditions. The results can help city planners to assess which factors could affect bicyclist resilience to adverse weather conditions - and which factors are of lesser importance in this respect. Moreover, we argue that there is an unobserved factor which plays an important role with regard to city resilience to adverse weather conditions. This unobserved factor could best be described as bicycle culture and reflects how "naturally" the bicycle is used as a means of transport within a city.

Third, a city ranking based on weather elasticities is compared to city rankings 
based on other cycling indices. We show that our weather-elasticity approach yields comparable results to alternative cycling indices based on stated preference surveys or external factors such as infrastructure. Moreover, we discuss the advantages and disadvantages of the different approaches.

In general, the resilience of cyclists to adverse weather conditions is very important, as it implies a greater dedication to cycling. However, if people frequently shift between cycling and other transport modes, it becomes more difficult for urban planners to provide an appropriate level of infrastructure for each mode of transport, as free spaces for new infrastructure are barely available in densely populated areas. Moreover, flexible public transport ticket structures could help in attracting cyclists to public transport if the weather is bad, instead of losing them to the less environmentally-friendly car. Our results provide additional insights into different urban cycling behaviors across cities, and thus help to directly address the needs of cyclists.

The structure of the paper is as follows. Section II reviews the literature. The weather elasticities of 30 German cities are calculated in Section III and in Section IV, we analyze potential determinants of these weather elasticities. In Section V, we compare the city ranking based on the weather elasticity index to other bicycle indices. Section VI concludes.

\section{Literature Review}

\section{A. General Cycling Differences Between Cities}

The share of bicycle trips can vary significantly between different countries and even between the cities of one country. In Australia, the United Kingdom, or the USA, the bike is used only for roughly $1 \%$ of all trips. In continental Europe, however, the bicycle is used more frequently. In Finland (9\%), Sweden (9\%), Germany (10\%), Denmark (18\%), and especially in the Netherlands (26\%), the modal share of cycling is significantly higher (Pucher and Buehler, 2012). Rietveld and Daniel (2004) outline a general framework of factors that can influence bicycle usage. These factors include individual driver characteristics, the generalized costs of cycling, the generalized costs of other transport modes, and local policies such as building high-quality and bicycle-dedicated infrastructure. Moreover, these authors state that intangible factors like the status of biking seem to influence the share of bicycle trips. They test empirically whether the factors of their explanatory framework indeed influence the share of bicycle trips, and find that physical aspects (e.g. altitude differences), population characteristics (e.g. age structure), ethnic composition, and policies such as those relating to the quality of cycling infrastructure or cyclist safety can impact on the share of bicycle trips. Other papers that have looked at various factors impacting on cycling shares or cycling rates include Hull and O'Holleran (2014) on perceptions of safety and comfort; Schoner et al. (2015) on infrastructure; Flynn et al. (2012), Böcker et al. (2013), or An et al. (2019) on weather conditions; or Parkin et al. (2008) on topography and socio-economic characteristics. For a more comprehensive review of factors influencing the modal share, however, we refer readers to Santos et al. (2013).

The differences in cycling shares can also, at least in part, be attributed to the history and perception of cycling within each country. In countries such as Australia, the bicycle is perceived mainly as a tool for recreational trips or sport (Daley and Rissel, 2011). In European and Asian countries, however, cycling is 
an established transport mode and often used for daily activities such as commuting (Rietveld and Daniel, 2004). Carstensen and Ebert (2012) argue that cycling cultures are influenced by political, social, and broader cultural aspects, while also acknowledging that geographical conditions could contribute to the formation of cycling cultures. In line with this, Cervero et al. (2019) argue that intangible factors, captured through fixed effects in their own regression model, can play an important role in determining the share of bike commuters. Possible intangible factors include a pro-bicycle culture. In their study of British cities, these intangible factors are still significant determinants of the share of bicycle commuters, even after controlling for potential explanatory factors such as the number of students, or educational levels of the general population within a city. A case study for Copenhagen in Denmark analyzes why biking is especially popular in this city, and one reason for this is the city's long history of biking and the associated culture (Gössling, 2013).

According to Rietveld and Daniel (2004), the fate of cycling is determined by more than just history, culture, topography, and climate. They outline that even Germany, Denmark and the Netherlands observed decreasing shares of bicycle trips from 1950 to 1975, a negative trend that could only be reversed through the implementation of bike-friendly transport and urban planning policies. Lanzendorf and Busch-Geertsema (2014) analyze changes in the modal share of bicycles across four German cities. For three of these cities, namely Munich, Frankfurt, and Berlin, they find a significant increase in the modal share of cycling between 2002 and 2008. They state that the greatest long-run benefits can be generated by a combination of infrastructure investments and dedicated marketing campaigns. A similar notion is also supported by Pucher et al. (2010) or Aldred and Jungnickel (2014). Based on an analysis of Dutch, Danish and German cities, Pucher and Buehler (2008) derive conditions that can help to promote cycling. They show that the best way to do so is to build cycling infrastructure that is separated from heavily travelled roads and intersections, as well as to establish traffic-calming measures in residential neighborhoods.

For Germany, Goetzke and Rave (2011) show that personal and city characteristics, as well as trip attributes, can influence cycling. Moreover, they demonstrate that bicycle culture, which they approximate by social network effects, can have a positive influence on cycling for shopping or recreational purposes, but it does not affect cycling for school, work, or errand trips. Moreover, the modal share of cycling for commuting trips appears not to be affected by policy variables, but decreases with the trip distance, bad weather, and the existence of rail transit alternatives. A flat topography can increase the bike share for school and work trips.

\section{B. The Different Effects of Adverse Weather Conditions on Cyclists of Different Regions}

There are several papers that estimate weather-condition effects on cycling (e.g. Hanson and Hanson, 1977; Miranda-Moreno and Nosal, 2011; Thomas et al., 2013). Moreover, it has been shown that there are effect differences between utilitarian and recreational bicycle traffic (Nosal and Miranda-Moreno, 2014; Zhao et al., 2018). Within this literature review, we focus on the papers that have analyzed regional differences between weather-condition effects on cycling. For a more detailed overview of the impact of weather conditions on cycling in general, 
we refer to Böcker et al. (2013).

While $90 \%$ of frequent winter cyclists in Calgary, Canada, indicated that they even feel comfortable riding their bike at $-20 \mathrm{C}$ or below (Amiri and Sadeghpour, 2015), such high numbers are unthinkable for other regions. For Sweden, Liu et al. (2015) show that perceptions of temperature variations differ significantly between different regions and seasons, and can lead to different travel behaviors.

The differences in the impact of weather conditions on cycling are also analyzed by Helbich et al. (2014), who look at the greater Rotterdam area. They find that temperature has a positive effect, and that wind and precipitation have a negative effect on the number of bicycles. Moreover, they find that the impact of weather conditions varies across space, and that it is generally stronger in remote areas than in more central, densely-populated areas. Böcker et al. (2019) conduct a comparison of weather-condition effects on mobility across four Dutch, Norwegian and Swedish city regions. They find that the statistical significance, magnitude, and sometimes even the direction of weather-condition effects can vary between different cities. They show that the transport regime within a city can significantly influence weather-condition effects. Good transport alternatives to cycling could thus lead to weather-condition effects being more pronounced, as potential cyclists can easily switch to transport means that are more comfortable under adverse weather conditions. Moreover, an increased presence of adverse weather conditions or cultural factors such as a pro-bicycle culture could strengthen the resilience to bad weather conditions. Using bikeshare data, Gebhart and Noland (2014) find out that trips starting from bikeshare stations close to a subway station are affected more strongly by rain or cold temperatures than trips starting from bikeshare stations that are not in vicinity of subway stations.

\section{Indices for Bicycle Friendliness}

To generate a suitable ranking for bicycle cities, various indicators can be used. There are indicators that measure the overall bicycle friendliness of a city, the bicycle infrastructure, or the satisfaction of the population with cycling conditions. Within this literature review, we focus on two indicators that are discussed in the scientific literature. This does not reflect negatively on other indicators - some of which are relevant to the context of our study and thus briefly discussed in Section $\mathrm{V}$ - that can generate valuable insights as well.

Winters et al. (2013) use GIS software to develop a "Bikeability Index". For this index, a composite indicator is formed from the five components of bicycle route density, bicycle route separation, connectivity of bicycle-friendly roads (number of intersections), topography, and the density of destinations (number of bikefriendly destinations) is built. The authors show that their Bikeability Index has a positive correlation with the modal share of bikes for commuting trips.

Zayed (2016) uses principal component analysis to highlight the attributes of the built environment that help to make a city bicycle-friendly. He finds that a city's bicycle-friendliness, as measured through cycling rates, correlates strongly with five different attributes of the built environment: city population, road network length, city form, city area, and the motorized transport modal split (public vs. private). This information is then used to calculate an index dubbed "Cycling Readiness" for 42 Egyptian cities, which can be used as an indicator for the readiness of Egyptian cities to become bike-friendly. 


\section{Contribution to the Literature}

Our paper then contributes to the literature in various ways.

We first propose an alternative way of ranking bicycle cities. While the existing bicycle city rankings mostly rely on stated preferences from surveys (e.g. ADFC bicycle climate index) or on external factors like infrastructure and safety (e.g. Zayed (2016), Copenhagenize Index, COYA bicycle index), we use revealed preference data - that is, the resilience of bicyclists to adverse weather conditions - to rank bicycle cities. Thus, the weather elasticity ranking is comparable to modal-share based rankings, but we argue that it can better capture the inherent dedication of cyclists to their mode of transport.

Second, we enrich the relatively scarce literature on regional differences in weather-condition effects on cycling (as presented in Section II.B) by analyzing weather effect differences for 30 German cities. The results allow us to assess in which cities cycling is viewed as more than just a fair-weather mode of transport - and which cities yield the largest share of fair-weather riders. Hence, the results can enhance our understanding of the importance of cycling for the whole transport system within a specific city.

Third, we do not look at the separate impact of selected weather conditions (e.g. temperature or precipitation) on cycling, as it is done in the papers outlined in Section II.B, but instead we estimate the impact of a single composite $a d$ verse weather indicator, which condenses information from five separate weather condition indicators. Due to the geometric aggregation of the five components, the composite adverse weather indicator is less compensatory and thus reflects the fact that extreme values in one weather condition component can outweigh the influence of other components. We thereby implicitly account for interaction effects between different weather conditions.

Fourth, by analyzing the relationship between weather elasticities and city characteristics, our paper relates to the literature on determinants of modal share differences (as presented in Section II.A) and determinants of weather condition effect differences (as presented in Section II.B). In our paper, however, we use the weather elasticities as a new dependent variable. Subsequently, we can determine whether the relationships between city characteristics and the calculated weather elasticities are similar to the relationships between city characteristics and modal shares or selected weather-condition effects.

Fifth, we compare the city ranking based on weather elasticities with other rankings based on stated preference surveys, or external factors such as infrastructure. The advantages and shortcomings of the weather elasticity ranking are discussed. Moreover, we outline policy implications that can be derived from the weather elasticity ranking, and we discuss what the ranking adds to the current debate on bike-friendliness.

\section{Weather Elasticity of Bicyclists}

\section{A. Data Sources}

In order to calcule cities' reactions to adverse weather conditions, we use hourly bicycle counts from 122 automated bicycle counting stations from 30 regions and cities within Germany. The sample period is 01.01.2017 to 31.12.2018. Given that Cools et al. (2010) or Zhao et al. (2019) have shown that the trip type influences the response to adverse weather conditions, we minimize the bias that 
might arise from measuring different types of bicycle traffic (e.g. utilitarian, recreational, mixed) by restricting our sample to counting stations that measure utilitarian bicycle traffic. Thus, our sample is basically a subsample of the one used in Wessel (2020), in which the underlying counter classification procedure is also described in more detail. The counting stations and cities that are considered in this article are displayed in Figure 1.

The bicycle counting stations of the sample are installed by Eco-Counter, a company that offers counting solutions for pedestrian and bicycle traffic flows. The accuracy of the counting stations is around $95 \%{ }^{1}$

Similar to Wessel (2020), Germany's National Meteorological Service (Deutscher Wetterdienst) provides hourly weather data for air temperature (measured at $2 \mathrm{~m}$ above ground, in $\mathrm{C}$ ), precipitation amount (in $\mathrm{mm}$ ), wind speed (measured at $10 \mathrm{~m}$ above the ground, in $\mathrm{m} / \mathrm{s}$ ), relative humidity (in \%), and cloud coverage (in eights).

\section{B. Creating a Composite Weather Indicator}

In order to more accurately compare the weather effects across different cities, we first condense multiple weather variables into a composite weather indicator that reflects information about actual weather conditions. This indicator can then be used to compare weather elasticities across different cities.

The composite indicator is calculated for each possible combination of city, day, and hour of the sample. It contains information from the variables temperature, precipitation, windspeed, relativehumidty, and cloudiness. Since these variables have different units of measurement, they are standardized to z-scores (Nardo et al., 2008). The standardized temperature variable is then multiplied by $(-1)$, so that positive values imply colder and thus worse weather conditions for cycling. For the other four weather variables, higher values - and subsequently positive values after standardization - already imply worse weather conditions (Böcker et al., 2013). Next, the five weather variables are aggregated using the geometric aggregation method with equal weights. The geometric aggregation method is less compensatory than the linear aggregation method and hence, it is more difficult to compensate for extreme weather conditions in one indicator through the other indicators (Greco et al., 2019). We argue that this is an important feature for weather data, because very heavy rain or extreme cold could easily prevent people from biking, even if all other weather conditions are normal.

For a more meaningful interpretation of the composite indicator, we normalize it with the min-max method, so that all values lie between 0 (best weather conditions) and 1 (worst weather conditions) (Nardo et al., 2008). ${ }^{2}$

\section{Estimating Cities' Reactions to Adverse Weather Conditions}

To estimate the impact of the composite weather indicator on bicycle ridership, we set up a log-linear regression model with the logarithm of the hourly bicycle counts as the dependent variable. Similar to the literature, observations with zero bicycle counts are changed to one, in order to calculate the logarithm; this

1 All counting data are owned by the cities and regions of the sample. We greatly appreciate the provision of the data by these cities and regions, and that Eco-Counter helped with data collection.

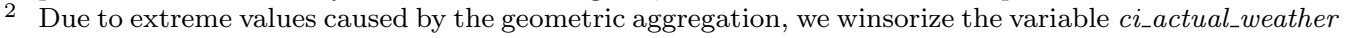
at the 0.998 quantile before the min-max transformation, in order to improve interpretability of the regression coefficients. In our case, this does not change the ranking of effect magnitudes. 


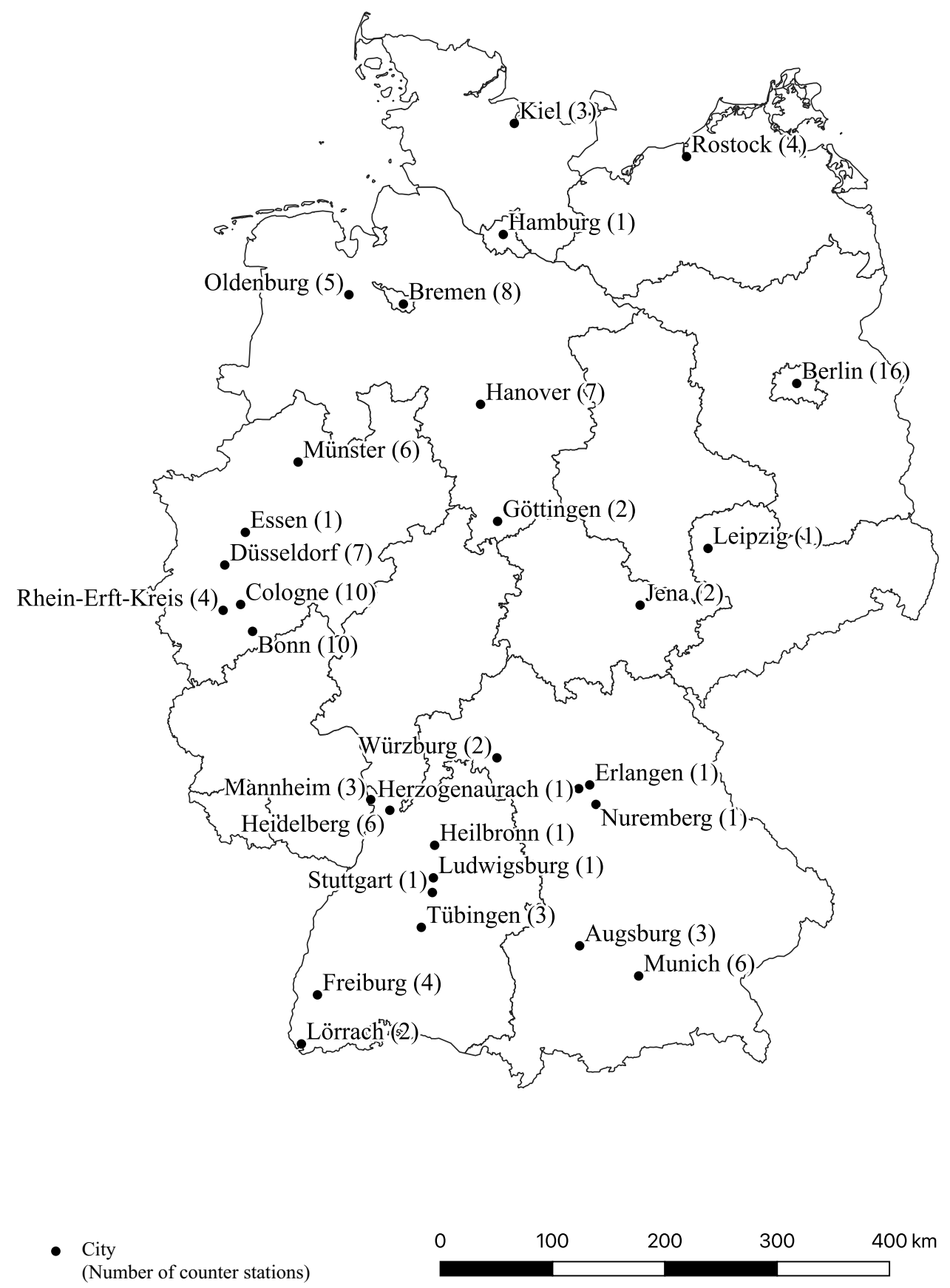

Figure 1. : Cities and Stations of the Sample 
amounts to $1.39 \%$ of all count observations. The composite weather indicator variable, which is the explanatory variable in which we are most interested, is included in the regression model by interacting it with the city dummies for each considered city. Thus, we can estimate the weather effects for each city separately. Similarly, the control variables accounting for general holidays, school holidays, and semester breaks, are also interacted with the city dummies, which allows for the impact of these holidays to vary across cities as well. In addition to these variables, we include bicycle-counting-station fixed effects, hour-of-day fixed effects (which are interacted with the city dummies to allow for different cycling patterns between cities), as well as fixed effects for the day of the week, month of the year, and year.

The estimated regression coefficients reflect the impact of a change in the composite weather indicator from 0 (best overall weather conditions in the sample) to 1 (worst overall weather conditions in the sample). Due to the extreme nature of such a weather change, we scale the coefficients to increase interpretability. In order to do so, we take the Q1 (25th percentile) and the Q3 (75th percentile) value of the composite weather indicator to model a more realistic weather change. The transformation of the original regression coefficients $\beta$ is as follows:

$$
\begin{aligned}
\text { weather elasticity } & =\left(e^{\beta \cdot\left(\text { weather }_{Q 3}-\text { weather }_{Q 1}\right)}-1\right) \cdot 100 \\
& =\left(e^{\beta \cdot(0.262406-0.209567)}-1\right) \cdot 100 .
\end{aligned}
$$

The resulting city-specific weather elasticities of cyclists, as well as the corresponding $95 \%$ confidence intervals, are presented in Figure 2. The point estimates reflect the change in bicyclist levels if the weather conditions change from the Q1 value of the composite weather indicator to the Q3 value of the composite weather indicator. That is, very roughly speaking, we deal with a change from relatively good weather to rather bad weather. The final ranking as well as the point estimates of the weather elasticities are also outlined in Table 2 in the Appendix.

The scaled weather elasticities enable us to rank the cities with respect to their resilience to bad weather conditions. In Oldenburg, a city with roughly 170,000 inhabitants, the regression coefficient of the composite weather indicator is not significantly different from zero at the $95 \%$ confidence level. This finding thus indicates that bicyclists in Oldenburg react the least to adverse weather conditions. Münster and Göttingen, two cities where students roughly make up $20 \%$ of the population, also yield a very low sensitivity to adverse weather conditions. All three cities have been labelled as "bicycle capital" in the past.

At the other end of the ranking spectrum, the city with the strongest reduction in bicycle traffic during bad weather is Würzburg, with Stuttgart and Herzogenaurach as runners-up.

As a sensitivity analysis, the weather elasticities were calculated only for weekday observations between 6 and 9 a.m. Although we have already excluded all bicycle counting stations that measure mainly recreational or mixed bicycle traffic from our sample in order to focus on utilitarian traffic, it is still possible that recreational bicyclists are measured as well. Additionally restricting the sample to observations of weekday morning peak hours should help us to further exclude recreational bicyclists from the sample. In the Appendix, these elasticities are presented in Figure 6, and Figure 7 compares the ranking based on all-day 


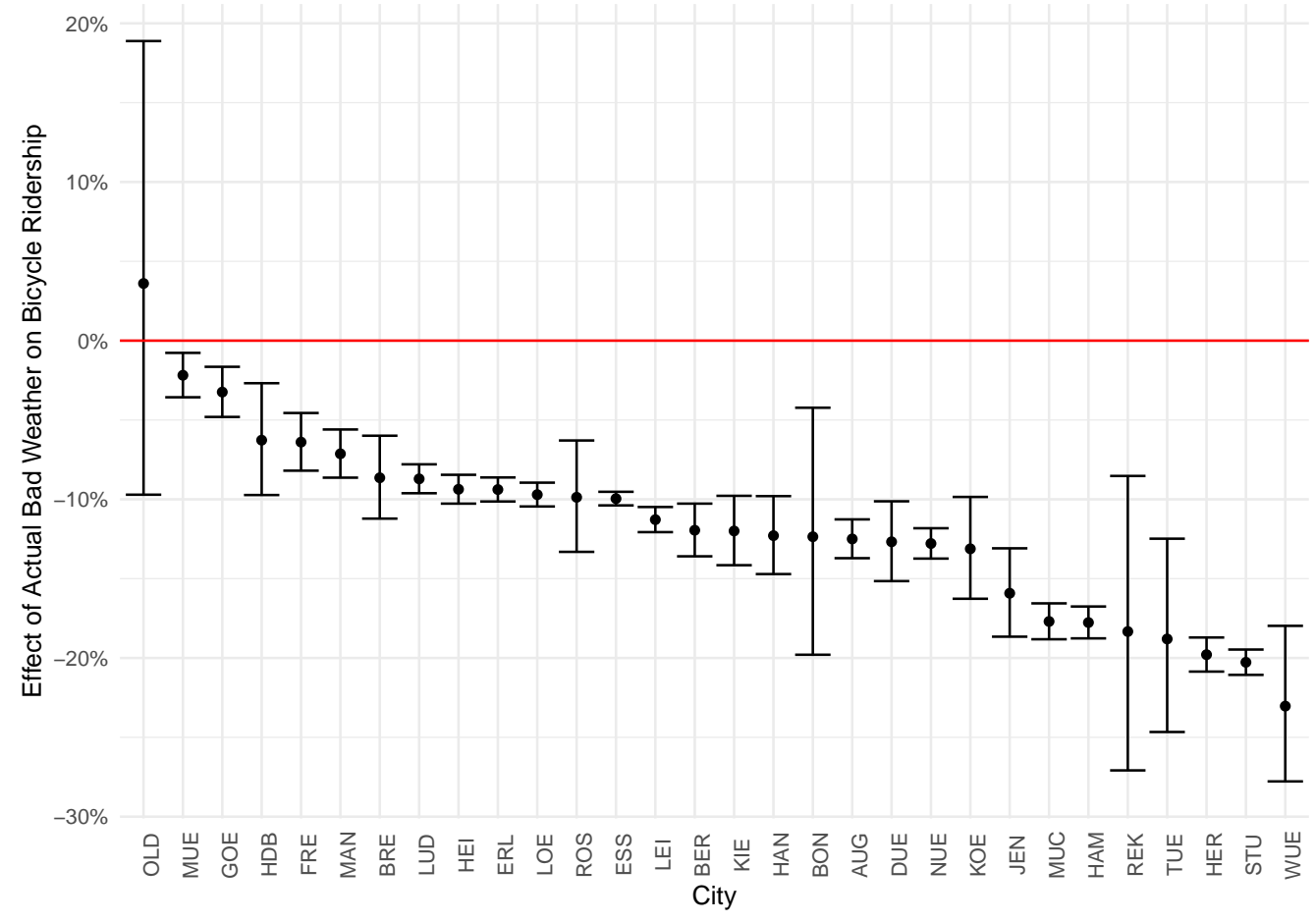

Figure 2. : Cities' Different Reactions to Bad Weather by City

bicycle counts to that based on weekday morning peak bicycle counts.

\section{Determinants of Weather Elasticities in Different Cities}

As we have seen in the previous section, the weather elasticity of cyclists differs significantly between cities. To explain these differences, there are many natural candidate variables that can be used as explanatory variables in a regression model, which are indeed often employed to explain the modal share of cycling (Santos et al., 2013). One drawback of the bicycle count data is that we cannot determine the impact of the generalized costs of transport (including the distance travelled) on weather elasticities, because such trip characteristics cannot be captured by the counting station data. To analyze their impact, other types of data (e.g. travel diaries, GPS data of bicycle trips) would be necessary and should thus provide an interesting direction for future research. In this paper, however, we focus on other important determinants that can impact on cycling behavior. In particular, we include the following variables at the municipal level. ${ }^{3}$

- Population density: In more densely populated areas, the density of potential destinations is also higher and, consequently, the distances between starting points and potential destinations are smaller (Winters et al., 2013). As the bicycle is used more for shorter distances $(<10 \mathrm{~km})$, more locations can be reached by bicycle in densely populated areas. Moreover, shorter trip lengths imply shorter trip times, and thus a reduced exposure to adverse weather conditions. Therefore, it can be assumed that people are more likely

3 Data sources for the variables employed in this analysis are given in Table 3 in the Appendix. 
to use their bicycle under adverse weather conditions if the surrounding area is more densely populated.

- Number of accidents: The number of accidents per 1,000 inhabitants includes all those that occurred in the respective municipality in 2017. The reasoning for including this variable is the fact that pedestrians and cyclists are the most vulnerable participants in (urban) traffic and are more exposed to severe traffic accidents. If people do not feel safe cycling to work or to the supermarket, they will use their bicycle less. Adverse weather can increase the risk of accidents and should thus be considered as an explanatory variable for weather elasticities. A detailed discussion of actual and perceived safety on cycling behavior is conducted by Hull and O'Holleran (2014).

- Share of population younger than 18 years: The extent to which people use their bicycle for daily trips depends on the available alternatives. People who are not old enough to drive legally cannot switch to car if the weather is bad (Rietveld and Daniel, 2004). In Germany, young people can obtain their drivers license when they are 17 years old, but have to be accompanied by someone older than 30 who has a driving license. People aged 18 and older are allowed to drive a car alone. Consequently, the share of people that are younger than 18 could explain weather elasticity differences between cities.

- Share of population between 18 and 25 years: For this variable, a similar reasoning as for the previous variable applies. Although all people in this group are formally allowed to drive, they are less likely to own a car or have one at their disposal, especially if they are students.

- Overall congestion level: Commuting by car becomes less attractive if a city is faced with higher automobile congestion. Travel time gains from commuting by car instead of commuting by bike decline, so that cycling becomes relatively more attractive. The index used to approximate congestion levels has been created by taking the minimum and maximum travel times provided by Google Maps for an average Thursday at 7:30 a.m. ${ }^{4}$ For each city, the Google Maps travel times and lengths were calculated for eight potential routes crossing the city center (north $\leftrightarrow$ south, east $\leftrightarrow$ west, north-east $\leftrightarrow$ south-west, north-west $\leftrightarrow$ south-east). Dividing the minimum free-flow speed by the congested speed yields the final index used in the regression model. A greater difference between average free-flow and congested speed would imply worse traffic conditions for car commuting, and thus result in a higher value for our congestion index. An index of 1.5, for example, would signify that a trip during peak hours takes $50 \%$ longer than the same trip without congestion.

Due to data unavailability, the above variables have to be collected at the city level. The following three variables are, however, collected at the less aggregated bicycle counting station level. They are based on GIS data on topography, cycle routes, and public transport stops. For the construction of these variables, a two kilometer radius is drawn around each bicycle counting station and the variance in altitude, density of cycle routes, and density of public transport stops are

4 The day chosen for this analysis is May 14th, 2020, which was lying in the future at the time when the data was collected (from May 4th to May 8th, 2020) 
calculated for each circle area. For the subsequent analysis, the data at the counting station level have to be aggregated at the city level.

- Elevation: The topography was identified as an important determinant of utilitarian cycling in the past. Utilitarian bicycle mobility is traditionally more present in regions with a relatively flat topography, as it is very difficult to comfortably climb steep hills (Rietveld and Daniel, 2004). The increasing market share of pedelecs has, however, decreased the influence of topography on cycling. Nevertheless, most people still use non-motorized bikes, and steeper slopes imply, on average, longer travel times and thus longer exposure to adverse weather conditions.

- Cycle route density: A good cycling infrastructure can be a strong incentive for people to use their bikes (Pucher and Buehler, 2008). Bicycle lanes could, however, also serve as a magnet, and only attract people who already use their bikes. Hence, new infrastructure could merely lead to route shifts by cyclists (Schoner et al., 2015). However, route shifts can still lead to shorter or more comfortable cycling and thus alleviate the discomfort caused by adverse weather conditions.

- Density of public transport stops: Good public transport provides an alternative to utilitarian cycling and can thus reduce bicycle ridership. Moreover, better alternatives make it easier to switch from bicycle to public transport in the event of bad weather. We use the average number of public transport stops (including bus, train, tram, etc.) in the two kilometer radius around each bicycle counting station for a given city. At larger public transport hubs such as main railway stations, each platform is counted as one stop. This gives larger public transport hubs a higher weight, which seems reasonable, as public transport quality at a main station is likely to be better than at a rural bus stop.

The variables described above are now used to explain the weather elasticities. Most explanatory variables are transformed to logarithms. Because the dependent variable is an elasticity, the corresponding regression coefficients have to be interpreted as follows. If the explanatory variable changes by $1 \%$, the weather elasticity changes by $\beta$ percentage points. The two variables that represent the share of young people in the total population are not transformed to logarithms, so that they can be interpreted as follows. If the share of young people increases by 1 percentage point, the weather elasticity changes by $\beta$ percentage points. Table 1 summarizes the results of two different regression models. In Column (1), the weather elasticities for all-day traffic at utilitarian bicycle counting stations are used as the dependent variable; in Column (2), the weather elasticities for only the morning-peak traffic at utilitarian bicycle counting stations are used as the dependent variable.

In regression models (1) and (2), the weather elasticities are not influenced significantly by either the population density, number of accidents, car possession, number of public transport stops, or the congestion index. However, the population density has the expected sign, as a higher density reduces the weather elasticity. This result corresponds to Helbich et al. (2014).

However, the share of people who are younger than 18 years old impacts positively on the weather elasticity. This group is not allowed to drive a car. Thus, 
a 1 percentage point increase in the share of people younger than 18 years old corresponds to an increase in the weather elasticity of 3.5 percentage points in model (1) and of 2.3 percentage points in model (2). In model (2), an increase in the share of people between 18 and 25 of one percentage point corresponds to an increase in the weather elasticity of 0.9 percentage points. Note that the weather elasticity is, in general, a negative value and for this reason, a positive regression coefficient leads to a less negative weather elasticity and thus to a higher resilience to adverse weather conditions. It appears that in cities with a younger population, fewer people are able to switch to alternative transport modes during bad weather, because the option of traveling by car is less likely to be available.

Table 1-: Determinants of Weather Elasticities

\begin{tabular}{lcc}
\hline & Weather Elasticity & Weather Elasticity \\
& $($ All-day Traffic] & (Weekday Traffic, 6-9 a.m.] \\
& -0.328 & $(2)$ \\
\hline ln_population_density & $(2.465)$ & -0.068 \\
& 5.714 & $(1.559)$ \\
ln_accidents & $(6.089)$ & -0.406 \\
ln_cars & -9.929 & $(3.851)$ \\
& $(6.478)$ & -4.672 \\
population_below_18 & $3.504^{*}$ & $(4.097)$ \\
& $(1.774)$ & $2.329^{*}$ \\
population_18_to_25 & 1.043 & $(1.122)$ \\
& $(0.606)$ & $0.914^{* *}$ \\
ln_elevation & -1.154 & $(0.383)$ \\
& $(1.558)$ & $-1.732^{*}$ \\
ln_cycle_routes & $7.188^{* *}$ & $(0.985)$ \\
& $(2.975)$ & $4.004^{* *}$ \\
ln_public_transport & -1.275 & $(1.881)$ \\
& $(0.971)$ & -0.483 \\
ln_congestion & -1.166 & $(0.614)$ \\
& $(8.559)$ & -5.925 \\
Constant & -69.769 & $(5.413)$ \\
& $(53.770)$ & -40.985 \\
Observations & 30 & $(34.004)$ \\
Adjusted R ${ }^{2}$ & 0.268 & 30 \\
Residual Std. Error $(\mathrm{df}=20)$ & 4.956 & 0.291 \\
F Statistic (df $=9 ; 20)$ & $2.177^{*}$ & 3.134 \\
\hline
\end{tabular}

${ }^{*} \mathrm{p}<0.1 ;{ }^{* *} \mathrm{p}<0.05 ;{ }^{* * *} \mathrm{p}<0.01$. Standard errors in parentheses.

The regression coefficient for the elevation variable is only significant in model (2). This seems plausible, because elevation is more serious for daily commuting trips where people are particularly keen to avoid perspiration. If altitude differences increase by $1 \%$, the weather elasticity decreases by 1.7 percentage points. Thus, a topography with steeper slopes corresponds to people switching more quickly from bike to other modes of transport. 
The cycle route variable has positive regression coefficients in both models. Thus, a higher density of cycle routes corresponds to less weather elastic cyclists. A good bicycle route network can lead to more trip alternatives for cyclists, so that they might be able to choose shorter or more sheltered routes. This result is in line with those of Lanzendorf and Busch-Geertsema (2014), Aldred and Jungnickel (2014) and Pucher and Buehler (2008), who find that more and better cycling infrastructure does indeed promote cycling.

The relatively low adjusted $R^{2}$ and the fact that there appear to be only a few significant explanatory variables for the weather elasticities could indicate the existence of other unobserved explanatory factors. As the city ranking based on weather elasticities is comparable and positively correlated to other bicycle rankings (more on this in Section $\mathrm{V}$ ), the validity of the weather elasticity ranking is convincing. We argue that one unobserved factor reflects bicycle culture, which could lead to a greater acceptance and willingness to use the bicycle, even if the circumstances are not ideal. Capturing this deep dedication to cycling is among the most important features of the weather elasticity ranking.

Although both regressions provide intuitively sound results, the regressions have clear limitations. Firstly, the number of observations is relatively low, as is the adjusted $R^{2}$. However, including more cities in the analysis could definitely improve the model fit and reliability of the estimated coefficients. As cities set up more and more bicycle counting stations, especially on utilitarian routes, this problem could be alleviated in the future.

Another drawback of this approach for approximating a revealed part of the bicycle culture in different cities is the potentially biasing placement of the automated bicycle counting stations. The exact location of the counting stations can influence what type of bicycle traffic is measured (utilitarian, recreational, or mixed) and, consequently, how strongly the measured bicycle ridership is affected by bad weather (e.g. Nosal and Miranda-Moreno, 2014). We attempt to circumvent this problem by including only bicycle counting stations that are classified as utilitarian. Moreover, we restrict the observations to peak hours in regression model (2), thus sharpening the focus on utilitarian traffic. Nevertheless, there might still be minor differences across utilitarian bicycle traffic flows of different counting stations. A higher number of automated bicycle counting stations at utilitarian locations per city could help to even out these differences and thus improve the overall reliability of such a bicycle climate index.

Moreover, this analysis, and most of the modal share analyses mentioned in Section 2.1 have in common that it is difficult to determine causality. We can state that a denser network of cycling routes corresponds to less weather-sensitive cyclists, but we cannot conclude that more cycling routes also cause cyclists to be less sensitive to adverse weather conditions. Although it is more likely that the causality rather goes this way than the reverse, we cannot rule out that regressors might be endogenous (Krizek et al., 2009; Schoner et al., 2015).

In general, it should also be noted that attitudes towards cycling can also differ significantly between countries (Pucher and Buehler, 2012). Therefore, the determinants of weather elasticities can also vary across countries and regions, thereby reducing the comparability of our study with studies from countries where cycling has a different standing in everyday life. 


\section{Comparison of Bicycle Indices}

Several bicycle indices have been created to measure the cycling conditions in cities. In this section, we compare different bicycle city rankings with our city ranking based on weather elasticities.

The Copenhagenize Index was created by the Copenhagenize Design Company, which specializes in advising municipalities on bicycle-related city and transport planning. The index is based on a score card with three categories (streetscape parameters, culture parameters, ambition parameters). While criteria are based mainly on the quality and quantity of bicycle infrastructure for the first category, the second category covers softer factors like modal share, safety, and cycling image. The third category focuses on the ambitions of political and public authorities to improve cycling conditions. The three categories are weighted equally for the overall index. Copenhagen, as in the name of the index, is ranked first in the 2019 edition of the ranking. The first German city is Bremen at rank 11, followed by Berlin at 15, and Hamburg at 20. The Copenhagenize Index only considers larger cities, which prevents a meaningful comparison with the weather elasticity ranking. The order of the three German cities, however, is similar for both rankings.

Another bicycle index is created by COYA, a German insurance company which, among other things, offers bicycle insurance. Their bicycle city index is a weighted index of 16 external factors impacting on bike ridership. ${ }^{5}$ The index is calculated for 50 different cities in Germany. As 21 of these cities are also included in our analysis, we can analyze how these 21 cities rank in the COYA ranking, compared to the weather elasticity ranking. The visualization of this comparison is displayed in Figure 3. For the weather elasticity ranking and the COYA ranking, Spearman's rank correlation rho is 0.82 . It is significantly different from zero at the $1 \%$ level (p-value: 0.000004 ).

The ADFC Bicycle Climate Index is (to a large degree) based on a stated preference survey in German cities and towns. Anyone can participate in the online survey and answer questions about the quality of bicycle infrastructure, cycling safety, comfort, as well as softer factors like the role of cycling, the extent the bicycle is used for trips, and the promotion of cycling. It should be noted that the survey is not representative of the actual population within cities. All cities from our analysis are also covered by the ADFC Bicycle Climate Index, thus simplifying the comparison. ${ }^{6}$ The visual comparison is provided in Figure 4. We estimate Spearman's rank correlation rho, which is 0.48 for the weather elasticity ranking and the ADFC ranking. It is significantly different from zero at the $1 \%$ level (p-value: 0.007 ).

Another indicator of bicycle utilization in a city or town is the modal share. The calculation of the modal share, however, requires extensive data about the mobility of people in a specific area. It would reveal the extent to which the bicycle is used as a means of transport, but does not include information from

5 Index scores of the COYA bicycle city index include weather, bicycle theft, investment and infrastructure quality, sharing, bicycle usage, safety, infrastructure, "no car day", fatalities, number of bicycle shops, number of bicycle sharing and rental stations, critical mass score, accidents, specialised roads and road quality score, number of shared bicycles, event score.

6 It should be noted that we take values from the 2018 edition of the ADFC bicycle climate index. For Herzogenaurach, we take a value from to the 2016 edition as Herzogenaurach is not considered in the 2018 edition. For the Rhein-Erft-Kreis, which is a German county, we take the average values over all cities of the Rhein-Erft-Kreis that are considered in the ADFC bicycle climate index. 


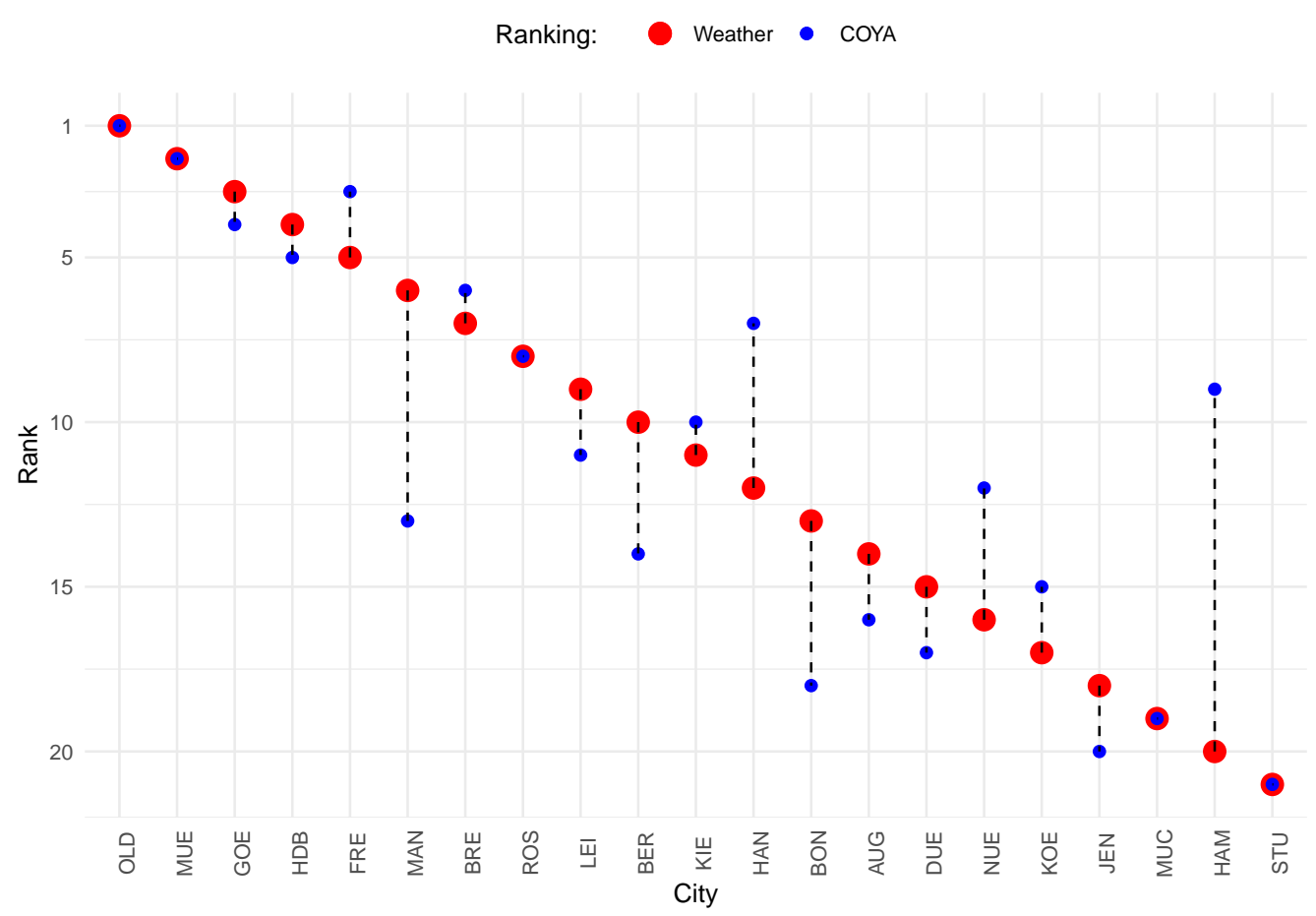

Figure 3. : Ranking Comparison (Weather Elasticities vs. COYA)

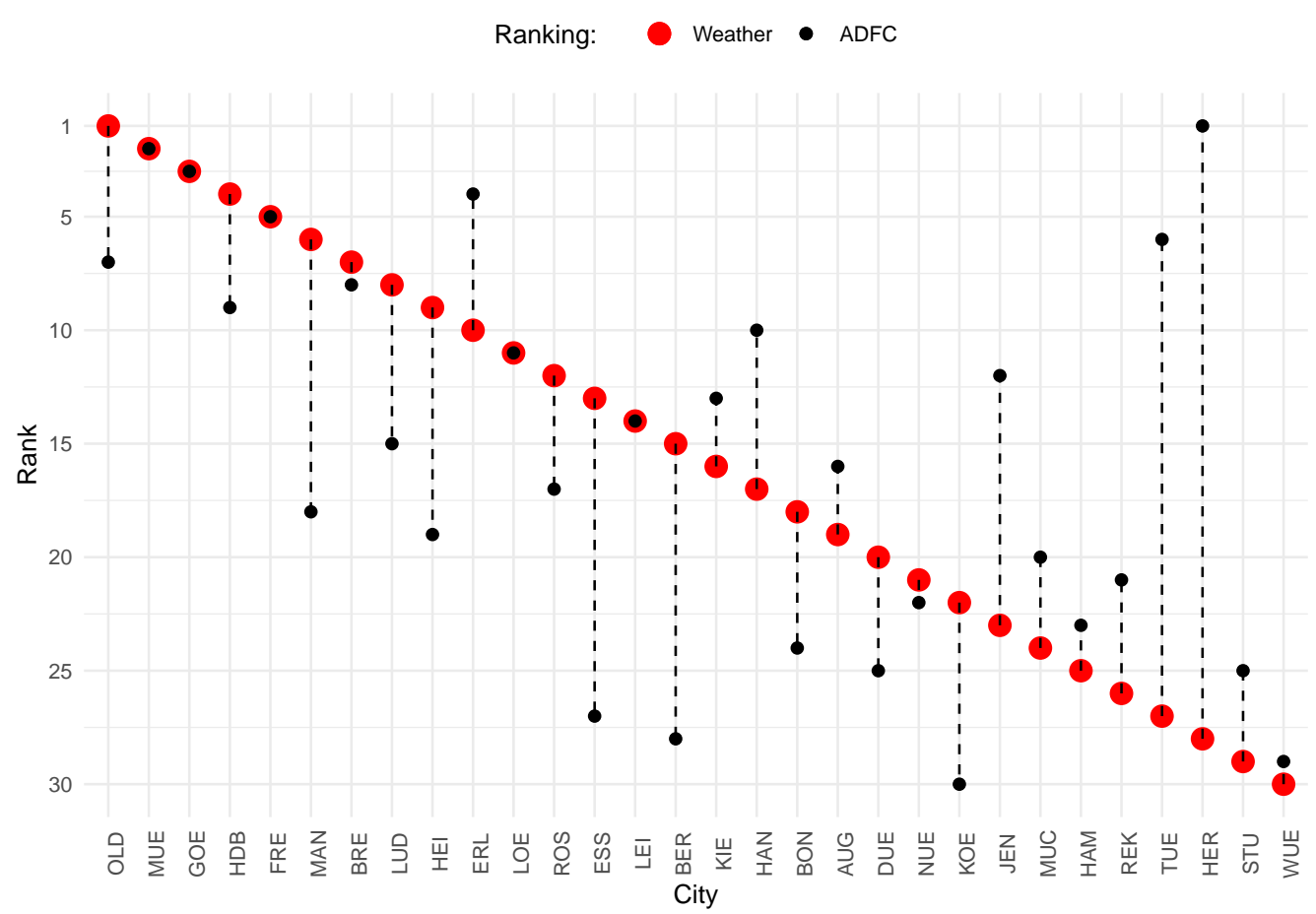

Figure 4. : Ranking Comparison (Weather Elasticities vs. ADFC) 
stated preference surveys or external factors. In this respect, the modal share can be compared to weather elasticities. The city-rank comparison of the modal share and the weather elasticities is illustrated in Figure 5. Spearman's rank correlation rho is 0.51 for these two rankings and significantly different from zero at the $1 \%$ level $(\mathrm{p}$-value $=0.004)$.

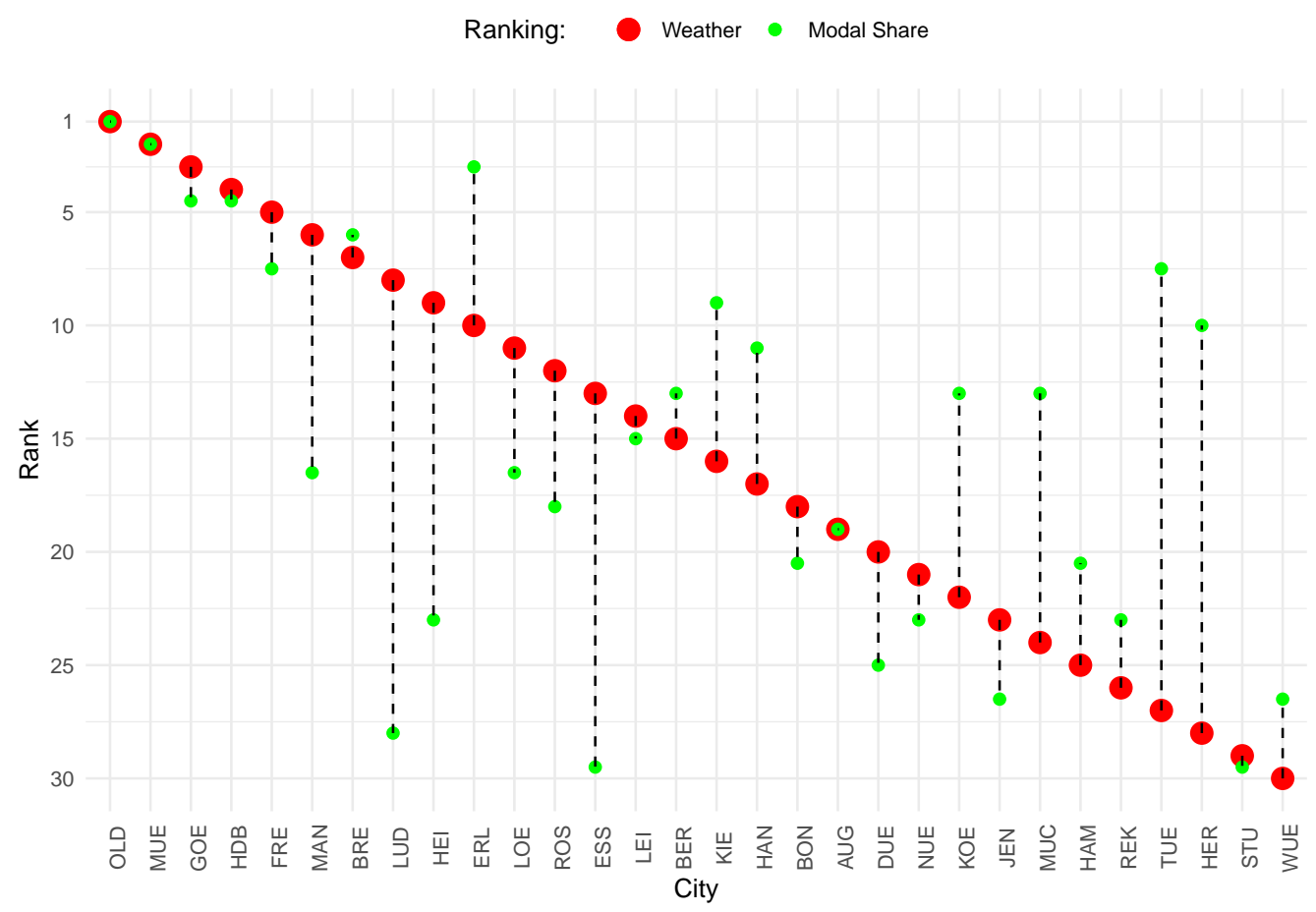

Figure 5. : Ranking Comparison (Weather Elasticities vs. Modal Share)

The three external indices listed in this section provide valuable insights for researchers, municipalities, and transport planners, but they also require a lot of data. The ADFC bicycle climate index is (mostly) based on a survey and reflects stated preferences. The COYA bicycle index requires objective data on municipal infrastructure, policy, and surrounding circumstances, as well as an adequate weighting scheme for the components. For the calculation of the bicycle modal share, a representative travel survey is needed. For all three rankings, data collection is a time-consuming and often expensive process. For the weather elasticity ranking, on the other hand, only two sources of data are needed, namely weather and bicycle counts. It could thus be argued that the data collection and preparation process for the weather elasticity ranking is less complex and quickerprovided that bicycle counting and weather stations are available, which, however, is indeed the case for many cities.

While the ADFC ranking is (mostly) based on stated preferences, the modal share ranking and the weather elasticity ranking are based on revealed preferences. Thus, they measure actual behavior and are less exposed to response bias. When comparing the modal share ranking to the weather elasticity ranking, it can be argued that the weather elasticity index can even more effectively capture the inherent dedication to cycling. As shown in Table 4 in the Appendix, both the 
ADFC and the modal share index can be better explained by the observable factors outlined in Section IV. The weather elasticity ranking, on the other hand, can help to reveal the existence of an unobserved bicycle culture within different cities. Therefore, the weather elasticity ranking can serve as a valuable addition to the literature, as well as to other bicycle rankings.

In line with the general evidence on cycling, our results indicate that the presence of more and better cycling routes increases the modal share of cycling, i.e. in our analysis, decreases the weather elasticity of cyclists. Consequently, policy makers should focus on the provision of a sufficient and good cycling infrastructure in order to promote cycling. As outlined in the introduction, infrastructure provision in cities is very difficult because of limited space. Our index yields information on how cyclists are affected by bad weather and thus to what extent the utilization of cycling infrastructure is reduced on days with bad weather. With regard to the discussion about so-called "environmental lanes" in German cities, the information from the weather elasticity index can be valuable to policy makers for their short-run planning when cycling infrastructure is rather fixed. To improve air quality in cities, the lanes of some highly frequented roads have been closed to regular cars and opened up to high-occupancy vehicles and cyclists in order to reduce emissions. However, closing one lane for the majority of car commuters reduces road capacity and could thus even increase congestion, if no alternatives to private motor vehicles are provided. If this lane, which can now be used by high-occupancy vehicles and cyclists, remains empty in bad weather situations due to cyclists' low resilience to bad weather, the measure would neither be effective, nor politically accepted. As the weather elasticity index reveals the cities in which cyclists are most affected by bad weather, a flexible provision of such environmental lanes could be a possible solution for these cities. Especially in winter months, when weather conditions are often not ideal, the environmental lane could rather be returned again to car drivers. This is also reasonable, as rain and darkness hours in the winter affect the driving behavior of cars and thus reduces road capacity even further (Brilon et al., 2005). Our index provides a valuable piece of information for determining for which German city this might be a viable option.

Furthermore, insights from the weather elasticity index could be used for public transport pricing. In cities where cyclists are not particularly resilient to adverse weather conditions, the bicycle will quickly be substituted by car or public transport if the weather is bad. The pricing structure of public transport, however, is often not very flexible and does not offer an attractive ticket option for such transport mode switchers. Many people commuting by public transport in Germany have a subscription for a monthly flat-rate ticket. As long as people use the ticket for all their commuting trips, the price is attractive. However, if people regularly switch between transport modes, these monthly flat-rate tickets become less attractive due to a higher price per trip. Buying single tickets each time the weather is bad might not be a viable option, as these tickets are often relatively expensive. Thus, a more flexible ticket type such as a reduced contingent ticket or a flat-rate ticket that is only valid in bad weather could be attractive. This option could be seasonal, such as in winter months, or even daily, if bad weather is forecasted, which has been shown to reduce cyclist levels (Kraemer et al., 2015; Wessel, 2020). If such flexible tickets were not available, more transport mode switchers would resort to the car during bad weather, thus exacerbating environmental problems. Of course, the analysis of mode choice behavior requires travel 
survey data and a different model setting in order to estimate cross-price elasticities, for example. However, our weather elasticity index gives an indication as to which German cities and towns it would be worthwhile for starting a pilot project with new ticket options that suit the weather-sensitive group of cyclists.

\section{Conclusion}

In this paper we present a new way to rank bicycle cities. The method is based solely on bicycle counter and weather data, which are used to estimate the elasticities of cyclists to adverse weather conditions for 30 German cities. The results indicate that there are significant weather elasticity differences between cities. In established bicycle cities like Münster, Oldenburg, and Göttingen, cyclists use their bike regularly even if the weather is bad. In other cities, however, cycling activity declines significantly under adverse weather conditions.

We show that cyclists are more resilient to adverse weather conditions in cities with a higher share of young people, and in cities with a denser cycle route network. The underlying regression is, however, limited by the relatively low sample size of only 30 cities that provided data from utilitarian bicycle counting stations. This problem could be reduced in the future when more cities are equipped with bicycle counting stations.

An unobservable factor that is likely to influence weather resiliency is the presence of a bicycle culture within a city or region. A higher resilience to bad weather reveals that cycling is already ingrained as an accepted and sometimes even indispensable mode of transport for daily trips. Thus, the weather elasticities can (at least in part) reveal the extent to which such thinking is already present within a city, and, consequently, the extent to which a bicycle culture prevails.

The city ranking based on the weather elasticity index is positively and significantly correlated to other bicycle rankings like the COYA bicycle ranking, which is based on external factors such as infrastructure, or the ADFC bicycle ranking, which is (mostly) based on a stated preference survey. Consequently, the weather elasticity ranking can adequately display differences in cycling behavior across cities, and relies only on weather and bicycle count data which are often collected anyway. Of course, the weather elasticity cannot replace other comprehensive surveys for bicycle travel, infrastructure, or policies, but it provides a reasonable and sound ranking of bicycle cities and provides valuable additional insights.

Moreover, the weather elasticity index can provide helpful insights to policy makers. Especially in cities where cyclists are highly weather-sensitive, new tariff structures for public transport that are more flexible and better suited to the needs of fair-weather cyclists could help in attracting these cyclists to public transport instead of leading them to use their own car if the weather is bad. Furthermore, a flexible provision of infrastructure, like giving more road capacity to cyclists on good days and more road capacity to cars on cold and rainy days, can be a good option.

In the future, the weather elasticity index could be calculated for additional cities, as more and more cities employ automated bicycle counting stations for traffic analysis. Subsequently, the sample size for analyzing the determinants of weather elasticities would rise, thereby improving the reliability of results. Additionally, an analysis of weather elasticities across cities in different countries could provide additional insights into the behavior of cyclists and the existence of local or national cycling cultures. 
An interesting direction for future research would be to not only use automated bicycle counting data when estimating weather elasticities, but also to include other types of data in the estimation. For this purpose, GPS trip data or data from bike-sharing companies like Nextbike could be used, as they might provide additional information about users profiles and (approximated) routes. Thereby, we could differentiate more precisely between utilitarian and recreational traffic flows.

\section{Acknowledgements}

The authors would like to thank Sebastian Specht, Alina Krämer, Dhurata Dervishaj, and Carina Gugel for their help in collecting and preparing data; Brian Bloch for his editing services; Peter Unterberg and Michael Magnus from Ecocounter for their helpful insights with regard to Ecocounter's automated bicycle counting stations; Thilo Grösch for providing the COYA bicycle index; and the bike managers of the cities for letting us use the data from their bicycle counting stations. 


\section{Appendices}

\section{A. Appendix}

Table 2-: Final Weather Elasticity Ranking

\begin{tabular}{|c|c|c|c|c|}
\hline \multirow[t]{2}{*}{ Rank } & \multirow[t]{2}{*}{ City ID } & \multirow[t]{2}{*}{ City } & \multicolumn{2}{|c|}{ Weather Elasticities } \\
\hline & & & $\begin{array}{l}\text { All Day Traffic } \\
\text { (Default) }\end{array}$ & $\begin{array}{c}\text { Traffic from } 6 \text { to } 9 \text { a.m } \\
\text { (Sensitivity) }\end{array}$ \\
\hline 1 & OLD & Oldenburg & 3.61 & 5.19 \\
\hline 2 & MUE & Münster & -2.18 & 0.32 \\
\hline 3 & GOE & Göttingen & -3.24 & -1.47 \\
\hline 4 & $\mathrm{HDB}$ & Heidelberg & -6.27 & -2.91 \\
\hline 5 & FRE & Freiburg & -6.39 & -2.67 \\
\hline 6 & MAN & Mannheim & -7.13 & -5.09 \\
\hline 7 & BRE & Bremen & -8.64 & -4.32 \\
\hline 8 & LUD & Ludwigsburg & -8.71 & -7.86 \\
\hline 9 & HEI & Heilbronn & -9.37 & -8.47 \\
\hline 10 & ERL & Erlangen & -9.38 & -4.32 \\
\hline 11 & $\mathrm{LOE}$ & Lörrach & -9.70 & -6.21 \\
\hline 12 & ROS & Rostock & -9.87 & -5.24 \\
\hline 13 & ESS & Essen & -9.96 & -4.39 \\
\hline 14 & LEI & Leipzig & -11.28 & -7.39 \\
\hline 15 & BER & Berlin & -11.95 & -6.83 \\
\hline 16 & KIE & Kiel & -11.99 & -4.56 \\
\hline 17 & HAN & Hanover & -12.29 & -5.57 \\
\hline 18 & $\mathrm{BON}$ & Bonn & -12.36 & -4.48 \\
\hline 19 & AUG & Augsburg & -12.50 & -7.23 \\
\hline 20 & DUE & Düsseldorf & -12.68 & -5.66 \\
\hline 21 & NUE & Nuremberg & -12.78 & -7.57 \\
\hline 22 & $\mathrm{KOE}$ & Cologne & -13.12 & -5.67 \\
\hline 23 & JEN & Jena & -15.92 & -6.42 \\
\hline 24 & MUC & Munich & -17.70 & -8.97 \\
\hline 25 & HAM & Hamburg & -17.76 & -9.15 \\
\hline 26 & REK & Rhein-Erft-Kreis & -18.33 & -8.32 \\
\hline 27 & TUE & Tübingen & -18.80 & -8.49 \\
\hline 28 & HER & Herzogenaurach & -19.79 & -7.89 \\
\hline 29 & $\mathrm{STU}$ & Stuttgart & -20.27 & -13.44 \\
\hline 30 & WUE & Würzburg & -23.03 & -14.68 \\
\hline
\end{tabular}

The ranking is based on the all-day bicycle counts (default). As described in Section III.C, the weather elasticities are scaled to reflect the change in bicycle ridership that occurs if the weather conditions change from the Q1 value of the composite weather indicator to the Q3 value. It should also be noted that the positive values for Oldenburg and Münster are not significantly different from zero at the $95 \%$ confidence level. 
Table 3-: Variable Description

\begin{tabular}{|c|c|c|}
\hline Variable $^{\mathrm{a}}$ & Description & Source \\
\hline $\begin{array}{l}\text { popu } \\
\text { densi }\end{array}$ & $\begin{array}{l}\text { municipalities' area in } \\
\mathrm{km}^{2} \\
\text { municipalities' } \\
\text { inhabitants }\end{array}$ & $\begin{array}{l}\text { Destatis data series } 11111-01-01-5-\mathrm{B} \\
\text { (Time: } 31.12 .2017 \text { ) } \\
\text { Destatis data series 12411-01-01-5-B } \\
\text { (Time: } 31.12 .2017 \text { ) }\end{array}$ \\
\hline accidents ${ }^{-}$ & $\begin{array}{l}\text { Statistic of road } \\
\text { accidents }\end{array}$ & $\begin{array}{l}\text { Destatis data series } 46241-01-03-5-\mathrm{B} \\
\text { (Year 2017) }\end{array}$ \\
\hline $\begin{array}{l}\text { car }^{-}--- \\
\text {ownership }\end{array}$ & $\begin{array}{l}\text { stock of motorized } \\
\text { vehilces and trailers }\end{array}$ & $\begin{array}{l}\text { Destatis data series } 46251-01-02-4-B \\
\text { (Time: } 01.01 .2018 \text { ) }\end{array}$ \\
\hline $\begin{array}{l}\text { population } \\
\text { by age }\end{array}$ & $\begin{array}{l}\text { population by gender } \\
\text { and } 17 \text { age groups }\end{array}$ & $\begin{array}{l}\text { Destatis data series } 12411-02-03-5-B \\
\text { (Time: } 31.12 .2017 \text { ) }\end{array}$ \\
\hline congestion & $\begin{array}{l}\text { Distance, minimum } \\
\text { and maximum time of } \\
\text { serveral urban routes }\end{array}$ & $\overline{\text { Google }}-\overline{-}$ \\
\hline èléva & $\begin{array}{l}\text { The standard deviation } \\
\text { of the altitude within a } \\
2 \mathrm{~km} \text { radius around } \\
\text { each bicycle counting } \\
\text { station. }^{\mathrm{c}}\end{array}$ & 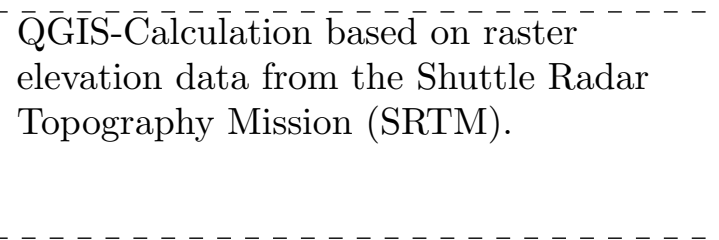 \\
\hline $\begin{array}{l}\text { cycle route } \\
\text { density }\end{array}$ & $\begin{array}{l}\text { The length of the cycle } \\
\text { route network within a } \\
2 \mathrm{~km} \text { radius around } \\
\text { each bicycle counting } \\
\text { station. }^{\mathrm{c}}\end{array}$ & $\begin{array}{l}\overline{\mathrm{Q}} \overline{\mathrm{G}} \overline{\mathrm{I}} \overline{\mathrm{S}}-\overline{\mathrm{C}} \overline{\mathrm{l}} \\
\text { OpenStree }\end{array}$ \\
\hline $\begin{array}{l}\text { public } \\
\text { transport } \\
\text { stop density }\end{array}$ & $\begin{array}{l}\text { The number of public } \\
\text { transport stops (bus, } \\
\text { train, tram, etc.) } \\
\text { within a } 2 \mathrm{~km} \text { radius } \\
\text { around each bicycle } \\
\text { counting station. }\end{array}$ & $\begin{array}{l}\overline{\mathrm{Q}} \overline{\mathrm{G}} \overline{\mathrm{IS}} \overline{\mathrm{C}} \overline{\mathrm{C}} \overline{\mathrm{l}} \mathrm{l} \text { culation based on } \\
\text { OpenStreetMap data. }\end{array}$ \\
\hline Coya- & $\begin{array}{l}\text { Bicycle Cities Index } \\
2019\end{array}$ & w.coya.com/ Dike/lantrad- \\
\hline$\overline{\mathrm{A}} \overline{\mathrm{D}} \overline{\mathrm{F}}$ & cities & 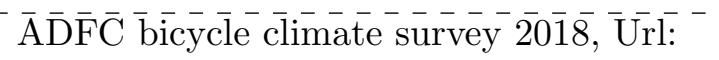 \\
\hline Rank & $\begin{array}{l}\text { marks from } \\
\text { good to } 5 \mathrm{po}\end{array}$ & https://www.fahrradklima-test.de \\
\hline $\bar{M} \overline{\mathrm{d}} \overline{\mathrm{a}} \overline{\mathrm{Sp}} \mathrm{p}$ & $\begin{array}{l}\text { The share of bicycle } \\
\text { trips in all trips. }\end{array}$ & $\begin{array}{l}\text { Various: Mobility in Germany } 20 \overline{17} \\
\text { survey, municipal traffic concepts }\end{array}$ \\
\hline
\end{tabular}

\footnotetext{
${ }^{a}$ For both variables, the amount is set in relation to the total population of the municipality to control for municipality size.

b Share of age group to total population calculated for each municipality.

c The variable is subsequently aggregated for the city level.
} 
Table 4-: Determinants of ADFC Bicycle Climate Index and Modal Share

\begin{tabular}{lcc}
\hline & ADFC & Modal Share \\
& $(3)$ & $(4)$ \\
\hline ln_population_density & 0.049 & -0.196 \\
& $(0.034)$ & $(0.127)$ \\
ln_accidents & 0.093 & 0.174 \\
& $(0.084)$ & $(0.314)$ \\
ln_cars & 0.136 & $-0.834^{* *}$ \\
& $(0.090)$ & $(0.334)$ \\
population_below_18 & $-0.067^{* *}$ & $0.275^{* * *}$ \\
& $(0.025)$ & $(0.092)$ \\
population_18_to_25 & $-0.029^{* * *}$ & $0.143^{* * *}$ \\
& $(0.008)$ & $(0.031)$ \\
ln_elevation & $0.039^{*}$ & $-0.308^{* * *}$ \\
& $(0.022)$ & $(0.080)$ \\
ln_cycle_routes & $-0.091^{* *}$ & $0.380^{* *}$ \\
& $(0.041)$ & $(0.154)$ \\
ln_public_transport & $0.044^{* * *}$ & $-0.128^{* *}$ \\
& $(0.013)$ & $(0.050)$ \\
ln_congestion & 0.009 & -0.063 \\
& $(0.119)$ & $(0.442)$ \\
Constant & $1.597^{* *}$ & 2.455 \\
& $(0.746)$ & $(2.774)$ \\
\hline Observations & 30 & 30 \\
Adjusted $\mathrm{R}^{2}$ & 0.516 & 0.670 \\
Residual Std. Error $(\mathrm{df}=20)$ & 0.069 & 0.256 \\
F Statistic $(\mathrm{df}=9 ; 20)$ & $4.435^{* * *}$ & $7.547^{* * *}$ \\
\hline
\end{tabular}

${ }^{*} \mathrm{p}<0.1 ;{ }^{* *} \mathrm{p}<0.05 ;{ }^{* * *} \mathrm{p}<0.01$. Standard errors in parentheses. 


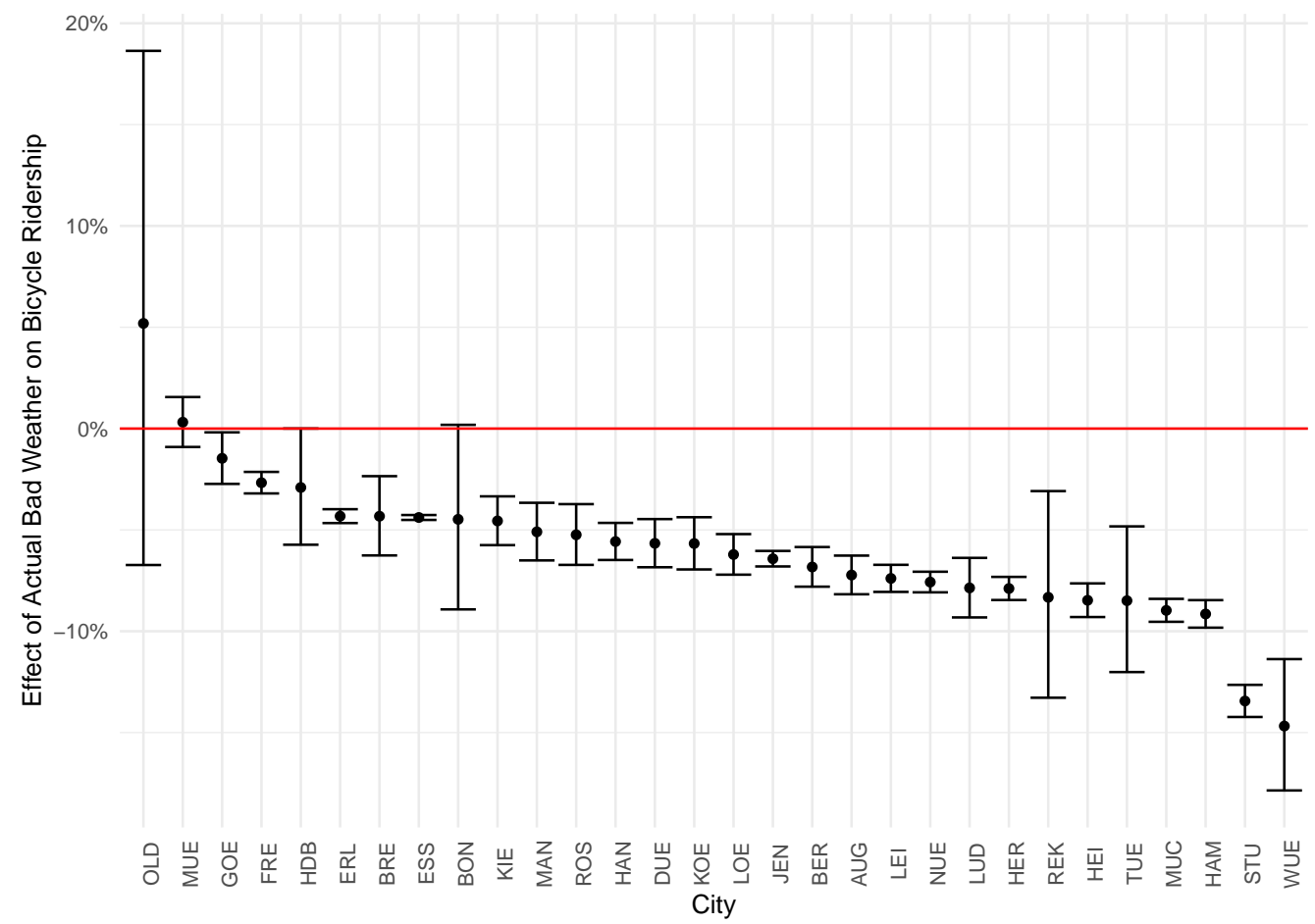

Figure 6. : Cities' Different Reactions to Bad Weather by City (Only Weekday Traffic from 6 to 9 a.m.) 


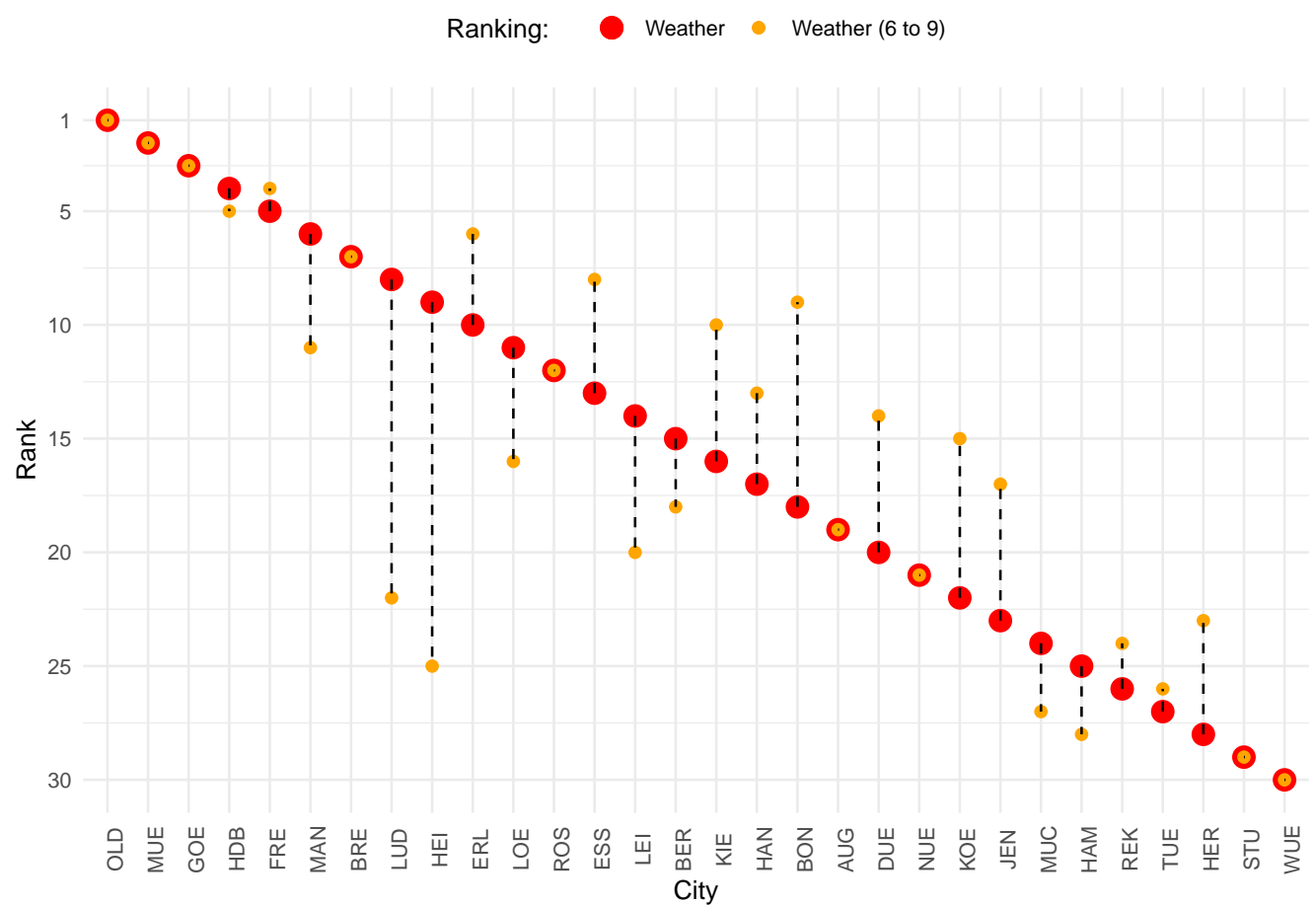

Figure 7. : Ranking Comparison (Weather Elasticities vs. Weather Elasticities for Weekday Traffic from 6 to 9 a.m.) 


\section{REFERENCES}

ADAC (2019). Studie: Tempo in Großstädten sinkt.

Aldred, R. and Jungnickel, K. (2014). Why culture matters for transport policy: the case of cycling in the uk. Journal of Transport Geography, 34:78-87.

Amiri, M. and Sadeghpour, F. (2015). Cycling characteristics in cities with cold weather. Sustainable Cities and Society, 14:397-403.

An, R., Zahnow, R., Pojani, D., and Corcoran, J. (2019). Weather and cycling in new york: The case of citibike. Journal of Transport Geography, 77:97 - 112.

Böcker, L., Dijst, M., and Prillwitz, J. (2013). Impact of everyday weather on individual daily travel behaviours in perspective: A literature review. Transport Reviews, 33(1):71-91.

Böcker, L., Uteng, T. P., Liu, C., and Dijst, M. (2019). Weather and daily mobility in international perspective: A cross-comparison of dutch, norwegian and swedish city regions. Transportation Research Part D: Transport and Environment.

Brilon, W., Geistefeldt, J., and Regler, M. (2005). Reliability of freeway traffic flow: A stochastic concept of capacity. Transportation and traffic theory, $16: 125-144$.

Carstensen, T. A. and Ebert, A.-K. (2012). Cycling Cultures in Northern Europe: From 'Golden Age'to 'Renaissance', volume 1, chapter 2, pages 23-58. Emerald Group Publishing Limited.

Cervero, R., Denman, S., and Jin, Y. (2019). Network design, built and natural environments, and bicycle commuting: Evidence from british cities and towns. Transport Policy, 74:153 - 164.

Cools, M., Moons, E., Creemers, L., and Wets, G. (2010). Changes in travel behavior in response to weather conditions: Do type of weather and trip purpose matter? Transportation Research Record, 2157(1):22-28.

Daley, M. and Rissel, C. (2011). Perspectives and images of cycling as a barrier or facilitator of cycling. Transport Policy, 18(1):211-216.

Flynn, B. S., Dana, G. S., Sears, J., and Aultman-Hall, L. (2012). Weather factor impacts on commuting to work by bicycle. Preventive Medicine, 54(2):122 124.

Gebhart, K. and Noland, R. B. (2014). The impact of weather conditions on bikeshare trips in washington, dc. Transportation, 41(6):1205-1225.

Goetzke, F. and Rave, T. (2011). Bicycle use in germany: Explaining differences between municipalities with social network effects. Urban Studies, 48(2):427437.

Gössling, S. (2013). Urban transport transitions: Copenhagen, city of cyclists. Journal of Transport Geography, 33:196 - 206. 
Greco, S., Ishizaka, A., Tasiou, M., and Torrisi, G. (2019). On the methodological framework of composite indices: A review of the issues of weighting, aggregation, and robustness. Social Indicators Research, 141(1):61-94.

Hanson, S. and Hanson, P. (1977). Evaluating the impact of weather on bicycle use. Transportation Research Record, 629:43-48.

Helbich, M., Böcker, L., and Dijst, M. (2014). Geographic heterogeneity in cycling under various weather conditions: evidence from greater rotterdam. Journal of Transport Geography, 38:38 - 47.

Hull, A. and O'Holleran, C. (2014). Bicycle infrastructure: can good design encourage cycling? Urban, Planning and Transport Research, 2(1):369-406.

Kraemer, J. D., Zaccaro, H. N., Roffenbender, J. S., Baig, S. A., Graves, M. E., Hauler, K. J., Hussain, A. N., and Mulroy, F. E. (2015). Assessing the potential for bias in direct observation of adult commuter cycling and helmet use. Injury Prevention, 21(1):42-46.

Krizek, K. J., Handy, S. L., and Forsyth, A. (2009). Explaining changes in walking and bicycling behavior: Challenges for transportation research. Environment and Planning B: Planning and Design, 36(4):725-740.

Lanzendorf, M. and Busch-Geertsema, A. (2014). The cycling boom in large german cities - empirical evidence for successful cycling campaigns. Transport Policy, 36:26-33.

Liu, C., Susilo, Y. O., and Karlström, A. (2015). The influence of weather characteristics variability on individual's travel mode choice in different seasons and regions in sweden. Transport Policy, 41:147 - 158.

Miranda-Moreno, L. F. and Nosal, T. (2011). Weather Or Not To Cycle: Temporal Trends and Impact of Weather on Cycling in an Urban Environment. Transportation Research Record, (2247):42-52.

Nardo, M., Saisana, M., Saltelli, A., Tarantola, S., Hoffmann, A., and Giovanni, E. (2008). Handbook on Constructing Composite Indicators: Methodology and User Guide. OECD Publishing.

Nosal, T. and Miranda-Moreno, L. F. (2014). The effect of weather on the use of north american bicycle facilities: A multi-city analysis using automatic counts. Transportation Research Part A: Policy and Practice, 66(1):213-225.

Parkin, J., Wardman, M., and Page, M. (2008). Estimation of the determinants of bicycle mode share for the journey to work using census data. Transportation, 35(1):93-109.

Pucher, J. and Buehler, R. (2008). Making cycling irresistible: Lessons from the netherlands, denmark and germany. Transport Reviews, 28(4):495-528.

Pucher, J. and Buehler, R. (2012). City Cycling. The MIT Press.

Pucher, J., Dill, J., and Handy, S. (2010). Infrastructure, programs, and policies to increase bicycling: An international review. Preventive Medicine, 50:106125. 
Rietveld, P. and Daniel, V. (2004). Determinants of bicycle use: do municipal policies matter? Transportation Research Part A: Policy and Practice, $38(7): 531-550$.

Santos, G., Maoh, H., Potoglou, D., and von Brunn, T. (2013). Factors influencing modal split of commuting journeys in medium-size european cities. Journal of Transport Geography, 30:127-137.

Schoner, J. E., Cao, J., and Levinson, D. M. (2015). Catalysts and magnets: Built environment and bicycle commuting. Journal of Transport Geography, 47:100-108.

Thomas, T., Jaarsma, R., and Tutert, B. (2013). Exploring temporal fluctuations of daily cycling demand on dutch cycle paths: The influence of weather on cycling. Transportation, 40(1):1-22.

TomTom (2019). Traffic index 2019.

Wessel, J. (2020). Using weather forecasts to forecast whether bikes are used. Transportation Research Part A: Policy and Practice, 138:537 - 559.

Winters, M., Brauer, M., Setton, E. M., and Teschke, K. (2013). Mapping bikeability: A spatial tool to support sustainable travel. Environment and Planning B: Planning and Design, 40(5):865-883.

Zayed, M. A. (2016). Towards an index of city readiness for cycling. International Journal of Transportation Science and Technology, 5(3):210-225.

Zhao, J., Guo, C., Zhang, R., Guo, D., and Palmer, M. (2019). Impacts of weather on cycling and walking on twin trails in seattle. Transportation Research Part D: Transport and Environment, 77:573 - 588 .

Zhao, J., Wang, J., Xing, Z., Luan, X., and Jiang, Y. (2018). Weather and cycling: Mining big data to have an in-depth understanding of the association of weather variability with cycling on an off-road trail and an on-road bike lane. Transportation Research Part A: Policy and Practice, 111:119-135. 
Westfälische Wilhelms-Universität Münster, Institute of Transport Economics, Working Paper Series

24. "A duopoly of transportation network companies and traditional radio-taxi dispatch service agencies"

by Thorsten Heilker and Gernot Sieg, November 2017

25. “Airport Efficiency in Pakistan - A Data Envelopment Analysis with Weight Restrictions"

by David Ennen and Irem Batool, November 2017

26. "Economic implications of phantom traffic jams: Evidence from traffic experiments"

by Kathrin Goldmann and Gernot Sieg, December 2018

27. "Evaluating the Transport-Mode-Specific Trade Effects of Different Transport Infrastructure Types"

by Jan Wessel, February 2019

28. "The impact of delays on the welfare effects of on-track competition: The case of transfer passengers with operator-tied tickets"

by Christina Brand and Gernot Sieg, December 2019

29. “Ride-Hailing Services in Germany: Potential Impacts on Public Transport, Motorized Traffic, and Social Welfare"

by David Ennen and Thorsten Heilker, January 2020

30. "Quantifying the phantom jam externality: The case of an Autobahn section in Germany"

by Kathrin Goldmann and Gernot Sieg, March 2020

31. "TEN-T Corridors - Stairway to Heaven or Highway to Hell?" by Kathrin Goldmann and Jan Wessel, June 2020

32. "Using weather forecasts to forecast whether bikes are used" by Jan Wessel, June 2020

33. "Some People Feel the Rain, Others Just Get Wet: An Analysis of Regional Differences in the Effects of Weather on Cycling"

by Kathrin Goldmann and Jan Wessel, July 2020

For a complete list of Working Papers published by Westfälische Wilhelms-Universität Münster, Institute of Transport Economics, please visit the website (http://www.ivmuenster.de) 